\title{
PERANCANGAN RUSUNAWA SEBAGAI HUNIAN SEHAT DAN BERKELANJUTAN BAGI MBR DI KAPUK, JAKARTA BARAT
}

\author{
Robby Indrajaya ${ }^{1)}$, Diah Anggraini ${ }^{2)}$ \\ 1)Program Studi S1 Arsitektur, Fakultas Teknik, Universitas Tarumanagara, indrajayarobby@gmail.com \\ 2) Program Studi S1 Arsitektur, Fakultas Teknik, Universitas Tarumanagara, diaha@ft.untar.ac.id
}

Masuk: 04-07-2021, revisi: 14-08-2021, diterima untuk diterbitkan: 23-10-2021

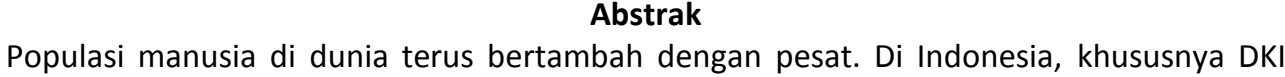
Jakarta, merupakan provinsi paling padat di Indonesia dengan total populasi mencapai 10 juta lebih penduduk. Hal ini menyebabkan penduduk di DKI Jakarta rentan membentuk permukiman kumuh di berbagai sudut kota karena banyak warga yang tidak memiliki kemampuan untuk membeli rumah yang layak sehingga dengan hadirnya permukiman kumuh tersebut akan mempengaruhi kesehatan penghuni dan wilayah kota itu sendiri. Oleh karena itu, proyek ini bertujuan untuk merancang sebuah alternatif hunian sehat dan layak di tengah kota sebagai suatu bentuk ketahanan (resilience) Kota Jakarta terhadap populasi penduduknya yang terus bertambah banyak, dan upaya untuk menerapkan sistem bangunan ramah lingkungan seperti penggunaan energi surya sebagai alternatif kebutuhan listrik, penggunaan kembali air hujan untuk kebutuhan air bersih penghuninya, serta memperbanyak lahan hijau kota baik di dalam tapak perancangan maupun dari lahan eks permukiman kumuh. Target dari proyek ini adalah Masyarakat Berpenghasilan Rendah (MBR) di DKI Jakarta, terutama di wilayah Kapuk yang merupakan kelurahan penduduk terbanyak di DKI Jakarta. Rumah susun ini dirancang dengan mengedepankan kesehatan, efisiensi kebutuhan ruang, adaptasi dengan kepadatan penduduk, dan ramah lingkungan. Metode yang digunakan yaitu deskriptif-kualitatif dengan pendekatan studi tipologi, baik dari bentuk dasar hunian, penyusun lantainya, serta studi kasus dari berbagai hunian yang ada di Jakarta. Dengan demikian, proyek ini dapat memberikan kenyamanan dan hunian yang layak bagi Masyarakat Berpenghasilan Rendah (MBR).

Kata kunci: Hunian Berkelanjutan; Hunian Sehat; MBR; Rusunawa

\begin{abstract}
The human population in the world continues to grow rapidly. In Indonesia, especially DKI Jakarta is the most densely populated province in Indonesia with a total population of more than 10 million people. This causes residents in DKI Jakarta to be vulnerable to forming slums in various corners of the city because many residents cannot buy decent houses so that the presence of slums will affect the health of residents and the city itself. Therefore, this project aims to design an alternative healthy and decent housing in the middle of the city as a form of resilience for the City of Jakarta against its growing population, and efforts to implement environmentally friendly building systems such as the use of solar energy as an alternative to needs. electricity, reuse of rainwater for the clean water needs of its residents, as well as increasing the green area of the city both in the design site and from the land of former slums. The target of this project is Low-Income Communities (MBR) in DKI Jakarta, especially in the Kapuk area which is the most populous urban village in DKI Jakarta. This flat is designed by prioritizing health, the efficiency of space requirements, adaptation to population density, and environmental friendliness. The method used is descriptivequalitative with a typology study approach, both from the basic form of the dwelling, the floor composition, as well as case studies from various dwellings in Jakarta. Thus, this project can provide comfort and decent housing for Low-Income People.
\end{abstract}

Key words: Healthy Housing; Low Income People (MBR); Rusunawa; Sustainable Housing 


\section{PENDAHULUAN}

\section{Latar Belakang}

Tingkat populasi manusia di dunia terus meningkat setiap tahunnya. Menurut PBB, dari 7,7 miliar penduduk terdapat 4,3 miliar penduduk $(56,2 \%)$ yang tinggal di wilayah perkotaan. Di Indonesia, terdapat 154,2 juta penduduk $(56,4 \%)$ yang tinggal menetap di wilayah perkotaan dari total jumlah penduduk sebanyak 273,5 juta pada tahun 2020. (WorldoMeter, 2020). Arus migrasi ke wilayah kota terus meningkat setiap tahunnya membuat wilayah kota semakin padat dan menimbulkan pengaruh yang besar bagi ekosistem perkotaan. (Gischa, 2020)

DKI Jakarta merupakan ibu kota negara dan pusat perekonomian di Indonesia yang memiliki luas $662,33 \mathrm{~km}^{2}$ dengan total populasi 10.557 .810 jiwa (2019). Sebagai pusat perekonomian, membuat masyarakat dari berbagai daerah bermigrasi ke Jakarta yang membuat Jakarta menjadi semakin padat setiap tahunnya. Dari data BPS, sampai tahun 2015 terdapat 3.647.238 penduduk yang melakukan migrasi seumur hidup dan telah menjadi penduduk ber KTP Jakarta. (Badan Pusat Statistik Indonesia, 2020) Tingginya tingkat migrasi ke Jakarta menimbulkan berbagai permasalahan seperti angka kemiskinan dan pengangguran yang tinggi, lahan permukiman yang semakin terbatas dan mahal, meluasnya permukiman kumuh akibat kemiskinan yang terus bertambah, serta kerusakan lingkungan. Menurut Staff Ahli Kementerian PUPR bidang sosial dan peran masyarakat, dengan populasi dunia yang terus meningkat diperkirakan dunia membutuhkan 1 miliar rumah baru pada tahun 2025. (Putra, 2016)

Tujuan dari proyek ini adalah mengatasi masalah hunian di Jakarta, seperti kurangnya lahan untuk dijadikan permukiman horizontal, harga lahan yang semakin tinggi yang tidak dapat dijangkau lagi oleh Masyarakat Berpenghasilan Rendah (MBR). Hunian ini dirancang menjadi sebuah hunian sehat dan layak di tengah kepadatan kota, dengan penggunaan energi matahari sebagai alternatif sumber listrik serta menggunakan kembali air hujan yang telah disaring sebagai langkah untuk menciptakan bangunan yang dapat berkontribusi pada keberlanjutan Kota Jakarta.

\section{Rumusan Permasalahan}

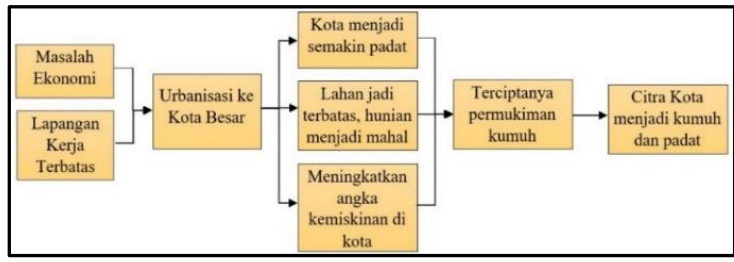

Gambar 1. Diagram Latar Belakang Proyek

Sumber: Dokumentasi Pribadi, 2021

a. Bagaimana prinsip-prinsip dan parameter hunian sehat dan layak bagi penghuninya?

b. Bagaimana arsitektur menerapkan prinsip-prinsip perancangan hunian yang sehat, layak, dan ramah lingkungan?

\section{KAJIAN LITERATUR}

Ekologi pertama kali dikemukakan Ernst Haeckel, berasal dari kata oikos dan logi yang berarti ilmu tentang rumah. Haeckel mendefinisikan ekologi sebagai seluruh ilmu tentang hubungan organisme dan lingkungannya (Buchori, 2012). Ekologi Urban menurut Carry Institute via Verma (2020) adalah suatu studi ilmiah tentang proses yang memengaruhi distribusi dan kelimpahan organisme, interaksi antara organisme dan transformasi dalam aliran energi dan materi. Ekosistem perkotaan mencakup aspek pertumbuhan penduduk dan infrastruktur pendukungnya, proses aglomerasi (pengumpulan beberapa elemen ke dalam suatu tempat), baik pada kota kecil, besar dan megacities (kota metropolitan). Aspek penting dari definisi ini adalah penekanannya pada 'proses' dan 'interaksi'. Desain ekologi menurut Van der Ryn pada 
tahun 1966, harus memenuhi kriteria: meminimalkan penggunaan energi \& material, mengurangi polusi, melestarikan habitat, membina komunitas, kesehatan, dan keindahan. (Herlambang, 2021)

Beyond Ecology adalah kemampuan untuk membaca sebuah kondisi ekosistem (lingkungan binaan yang penuh dengan objek ekosistem) dan mengusulkan solusi keruangan yang mampu menjawab tantangan konsep ekologi masa depan yang memiliki prinsip kebaikan dan kehidupan (bangunan dirancang harus sebagai 'rumah' - 'oikos' bagi manusia di bumi.) Terdapat 6 parameter beyond ecology dalam arsitektur (Sutanto, 2021) yaitu:

a. Energy and Emission : kemampuan untuk menerapkan zero $\mathrm{CO} 2$ emision dalam operasional bangunan dan meminimalisi efek karbon dalam material dan konstruksi

b. Adaptation : kemampuan melakukan riset dan desain yang berkaitan dengan berbagai dampak seperti naiknya suhu bumi, naiknya permukaan air laut, kekeringan, banjir, kelangkaan pangan dan perubahan populasi

c. Resilience : kemampuan untuk membangun kelanjutan hunian dan pemulihan cepat setelah kejadian guncangan, bencana alam, gangguan listrik dan iklim

d. Sustainable digital : kemampuan untuk melihat data-data lingkungan sebagai big data dalam menentukan taktik dan strategi dalam membangun kualitas spasial

e. New technology: kemampuan memanfaatkan teknologi terbaru untuk meningkatkan kualitas dan terapan ruang konstruksi dan program bangunan

f. Context: kemampuan dalam melihat posisi "tempat" dalam hubungan dengan lingkungan (Flora- Fauna- Biotic- Abiotic) dimana sebuah konfigurasi keruangan akan ditempatkan.

\section{Kepadatan Penduduk}

Perserikatan Bangsa-Bangsa (PBB) merilis laporan yang menyebutkan bahwa populasi dunia diperkirakan akan bertambah sekitar 2 miliar orang dalam 3 dekade mendatang (tahun 2050). Dalam laporan PBB yang berjudul "World Population Prospects 2019" yang dirilis oleh Departemen Urusan Ekonomi dan Sosial PBB, pada Juni 2019, jumlah populasi manusia di dunia akan bertambah dari 7,7 miliar menjadi 9,7 miliar pada 2050. Dalam laporan PBB disebutkan bahwa lebih dari 50\% jumlah penduduk tersebut akan berasal dari sembilan negara, termasuk Indonesia. (National Geographic Indonesia, 2019)

Diperkirakan pada tahun 2025 diperlukan 1 miliar rumah baru dengan estimasi biaya 9-11 triliun dollar. Pada saat ini terdapat $25 \%$ penduduk dunia tinggal di permukiman kumuh dan permukiman informal. Oleh karena itu perumahan adalah pendekatan utama pembangunan berkelanjutan. PBB meluncurkan program SDGs untuk pembangunan berkelanjutan berdasarkan hak asasi dan kesetaraan untuk mendorong pembangunan sosial ekonomi dan lingkungan hidup. Terdapat 17 tujuan dalam pembangunan berkelanjutan SDGs 2030. Indonesia melalui Bappenas menyatakan komitmen serius dalam melaksanakan SDGs 2030. (Menuju Pembangunan Permukiman yang Berkelanjutan, Tugas 2 Kajian Arsitektur Kota, 2020)

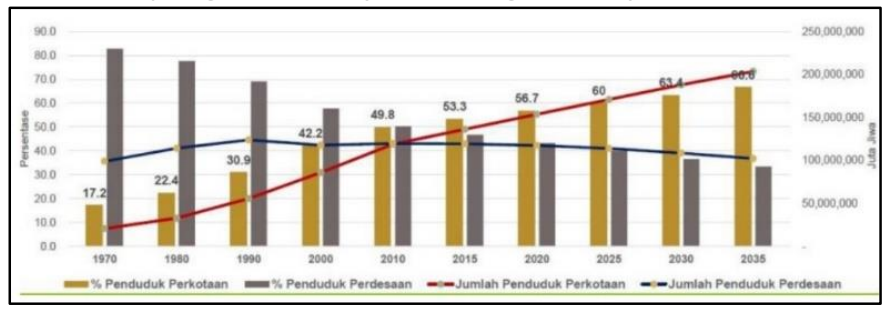

Gambar 2. Grafik Perkiraan Penduduk Perkotaan hingga tahun 2035 Sumber : Materi Kajian Arsitektur Kota 07/04/2020 


\section{Hunian Sehat}

Rumah sehat adalah rumah yang memenuhi kriteria minimal: akses air minum, akses jamban sehat, lantai, ventilasi, dan pencahayaan (Kementerian Kesehatan Republik Indonesia, 2013). Program Kotaku (Kota Tanpa Kumuh) bertujuan untuk mempercepat penanganan permukiman kumuh di perkotaan dan mendukung terciptanya hunian sehat dengan "Gerakan 100-0100", yaitu 100 persen akses air minum layak, 0 persen permukiman kumuh, dan 100 persen akses sanitasi layak. (Kementerian Pekerjaan Umum dan Perumahan Rakyat, 2010). Dalam program ini ada beberapa indikator yang digunakan Kementerian PUPR dalam membuat hunian sehat :

a. American Public Health Association

1) Memenuhi pencahayaan, pengudaraan yang baik, ruang gerak yang baik dan tidak terdapat kebisingan yang mengganggu. (kebutuhan fisiologis)

2) Memenuhi ruang privasi yang cukup bagi setiap orang, komunikasi yang baik di dalam rumah (kebutuhan psikologis)

3) Mencegah penularan penyakit menular di dalam rumah dengan menyediakan air bersih, pengolahan tinja dan limbah yang baik, bebas dari hama seperti tikus, memenuhi sinar matahari yang cukup, serta penghawaan yang cukup.

4) Membuat bangunan dengan pondasi, lantai, dinding, langit-langit, atap, dan konstruksi yang kokoh, stabil, untuk melindungi penghuni dari berbagai gangguan.

b. Dirjen Cipta Karya telah menetapkan bahwa komponen yang harus dimiliki oleh rumah sehat adalah: pondasi, lantai, dinding, langit-langit, dan atap rumah harus kokoh,stabil dan dapat melindungi penghuni dari berbagai gangguan, serta jendela, pintu dapat memasukkan cahaya matahari ke dalam rumah dan berfungsi sebagai bukaan untuk mengalirkan udara. (Dirjen Cipta Karya , 1992)

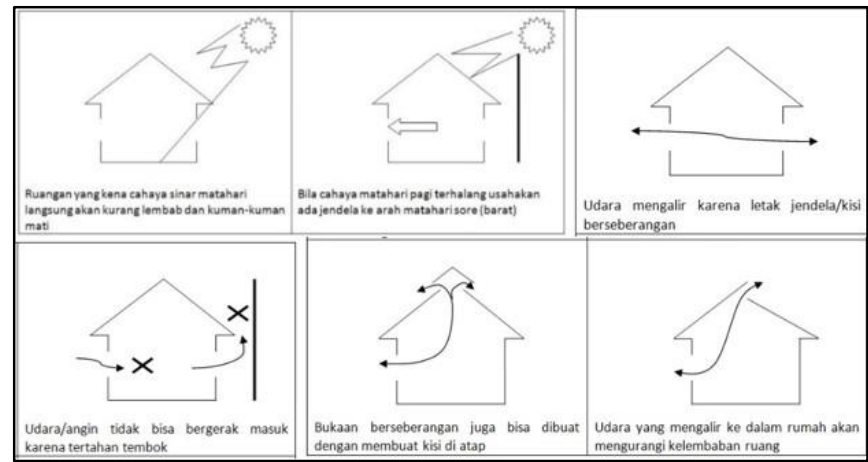

Gambar 3 Pencahyaan alami dan sirkulasi udara alami pada rumah sehat Sumber : kotaku.pu.go.id

Berdasarkan "Pedoman Teknis Pembangunan Rumah Sederhana Sehat", kebutuhan 1 orang dewasa dalam ketentuan rumah sehat adalah $9 \mathrm{~m}^{2}$ dengan tinggi plafon $280 \mathrm{~cm}$. (Kepmen Permukiman dan Prasarana Wilayah no 403/KPTS/M/2002 tentang "Pedoman Teknis Pembangunan Rumah Sederhana Sehat, 2002)

\section{Hunian Berkelanjutan}

Perwujudan dari ekologi arsitektur adalah bangunan yang berwawasan lingkungan yang sering disebut sebagai arsitektur berkelanjutan. Menurut Heinz Frick dalam Sukawi 2008, pola perencanaan arsitektur berkelanjutan (eko-arsitektur) yaitu menciptakan penghijauan pada kawasan sebagai paru-paru hijau, menggunakan bahan bangunan dengan intensitas energi seminimal mungkin, bangunan diarahkan menurut orientasi timur barat dan menghadap utara selatan sehingga sinar matahari tidak menyilaukan, dinding dan atap bangunan dapat memberi 
perlindungan terhadap panas dan memperhatikan sirkulasi udara alami sehingga bisa menghemat pemakaian energi, memajukan sistem konstruksi bangunan dengan menjamin kestabilan struktur bangunan, memperhatikan proporsi ruang, menjamin bangunan tidak menimbulkan masalah lingkungan, dan merancang bangunan yang ramah penghuni bagi anakanak, orang tua, dan orang disabilitas. (Sukawi, 2008)

Skala yang digunakan dalam hunian berkelanjutan pada skala mikro yaitu :

a. Lingkungan : memastikan penghematan energi dan air, mencegah hal-hal berbahaya (polusi) dan meningkatkan ketahanan dari rumah.

b. Sosial : memberdayakan masyarakat, menciptakan rasa kebersamaan, menyediakan akses ke ruang publik, dan memenuhi kebutuhan spesifik (terkait jenis kelamin dan kesehatan).

c. Budaya : meningkatkan estetika, dan keragaman di tempat hunian, membantu kreativitas masyarakat melalui fasilitas seperti olahraga terjangkau, membantu peralihan daerah kumuh masyarakat menuju ke hunian yang layak

d. Ekonomi : memastikan keterjangkauan perumahan bagi kelompok sosial yang berbeda, menyediakan tempat tinggal memadai untuk meningkatkan produktivitas kerja, memastikan perumahan terintegerasi dengan pekerjaan, memperkuat ketahanan hunian. (Rosilawati, 2016)

\section{Hunian Terjangkau}

Rumah tapak (landed houses) yang dibangun secara horizontal membutuhkan lahan yang luas, sehingga pada saat ini, lahan yang tersedia di wilayah perkotaan semakin terbatas dan harga lahan yang semakin mahal membuat pemerintah mulai mengganti bentuk rumah yang lebih praktis dan tidak membutuhkan lahan yang terlalu besar, yaitu rumah susun. Pembangunan rumah susun adalah salah 1 cara yang dapat digunakan untuk menyelesaikan kebutuhan perumahan masyarakat di daerah perkotaan besar yang jumlah penduduknya terus bertambah pesat setiap tahunnya. (Rosilawati, 2016)

Penyelenggaraan perumahan dan kawasan permukiman dilakukan untuk memberikan suatu kepastian hukum pada masyarakat, mengembangkan dan menata suatu wilayah, serta mengatur penyebaran penduduk melalui pertumbuhan lingkungan hunian dan kawasan permukiman sesuai dengan tata ruang wilayah terutama bagi MBR (Undang-Undang No 11 tahun 2011 tentang Perumahan dan Kawasan Permukiman)

Beberapa jenis rumah susun berdasarkan UU no 20 tahun 2011 tentang rumah susun yaitu:

a. Rumah Susun Umum: Rumah susun yang diselenggarakan untuk memenuhi kebutuhan rumah bagi Masyarakat Berpenghasilan Rendah (MBR).

b. Rumah susun khusus: Rumah susun yang dirancang untuk suatu kebutuhan khusus

c. Rumah susun Negara: Rumah susun yang dibangun dan dimiliki negara, digunakan sebagai tempat tinggal, serta sebagai penunjang pelaksana pejabat pemerintahan

d. Rumah Susun Komersial: Rumah susun yang dibangun untuk kepentingan komersial dan mendapat keuntungan. (Undang-Undang No. 20 tahun 2011 tentang Rumah Susun)

Ukuran Sarusun (Satuan Rumah Susun) didasarkan pada kebutuhan ruang/jiwa manusia yaitu 9 $\mathrm{m}^{2}$ dan fungsi rumah susun harus mampu mewadahi berbagai aktivitas pokok dari setiap penghuninya dengan ruang dengan luasnya yang terbatas. (Hartinasari, 2018)

\section{Masyarakat Berpenghasilan Rendah (MBR)}

Masyarakat Berpenghasilan Rendah (MBR) adalah kelompok masyarakat yang kemampuan daya belinya terbatas, dan membutuhkan bantuan dari pemerintah baik pusat dan daerah untuk dapat memiliki rumah. (Undang-Undang No 11 tahun 2011 tentang Perumahan dan Kawasan 
Permukiman) Pemerintah menetapkan batas penghasilan masyarakat berpenghasilan rendah (MBR) maksimal Rp8.000.000, - /bulan jika ingin mendapatkan program kpr rumah tapak dan rumah susun subsidi dari pemerintah. (Keputusan Menteri PUPR no 242/KPTS/M/2020, 2020) Menurut Menteri PUPR, Basuki Hadimuljono, penyediaan rumah subsidi pemerintah untuk MBR, "MBR bukan berarti miskin tapi keluarga muda bergaji Rp 4 juta - Rp 7 juta," (Himawan, 2016)

\section{METODE}

Metode yang digunakan untuk penelitian ini yaitu metode deskriptif-kualitatif dengan pendekatan studi tipologi dari teori bentuk dasar hunian, penyusunan lantainya dan studi kasus dari berbagai hunian yang ada di Jakarta. Data dikumpulkan berdasarkan kategori bangunan rusunawa, perbandingan beberapa studi kasus kemudian dapat diambil suatu kesimpulan tentang tipe dan bentuk yang tepat dalam merancang rusunawa sehingga ide perancangan dapat menjadi sebuah tanggapan dalam permasalahan yang diangkat.

\section{DISKUSI DAN HASIL}

Proyek "Rusunawa Sehat Berkelanjutan Bagi MBR di Kapuk, Jakarta Barat" ini hadir sebagai salah 1 alternatif hunian untuk kawasan berkepadatan penduduk tinggi di Jakarta, dengan program yang direncanakan untuk membantu meningkatkan kualitas hidup masyarakat dari permukiman kumuh menjadi permukiman sehat dan membantu penghuni dari sisi ekonomi seperti tempat usaha bagi penghuni untuk berusaha sesuai dengan kemampuan yang dimiliki, sistem listrik dari solar panel yang membantu menghemat pengeluaran setiap unit hunian, penggunaan kembali air hujan untuk menghemat ketersediaan air bersih dan pengeluaran penghuni.

\section{Analisis Kawasan}

Kawasan yang dipilih yakni Kelurahan Kapuk, Cengkareng. Kelurahan Kapuk adalah kelurahan dengan jumlah penduduk penduduk terbanyak di Provinsi DKI Jakarta. Kelurahan Kapuk memiliki 16 RW dengan jumlah penduduk sebanyak 172.796 jiwa dan jumlah KK = 54.716, sehingga ratarata jumlah anggota per keluarga adalah = 3,15 jiwa/keluarga. Maka bisa diartikan bahwa jumlah anggota dalam 1 keluarga = 3 - 4 orang. (Badan Pusat Statistik Jakarta Barat, 2020)

Tabel 1. Jumlah penduduk Kecamatan Cengkareng

\begin{tabular}{lll}
\hline No & Kelurahan & Jumlah Penduduk (jiwa) \\
\hline 1 & Duri Kosambi & 104.310 \\
\hline 2 & Rawa Buaya & 77.867 \\
\hline 3 & Kedaung Kaliangke & 39.842 \\
\hline 4 & Kapuk & 172.796 \\
\hline 5 & Cengkareng Timur & 111.467 \\
\hline 6 & Cengkareng Barat & 94.874 \\
\hline & Total & 601.156 \\
\hline
\end{tabular}

Sumber: Badan Pusat Statistik Jakarta Barat, 2020

Jika dilihat dengan Peta Rencana Kota DKI Jakarta, di RW 12 terdapat wilayah yang merupakan RTH Kota telah berubah menjadi kawasan permukiman kumuh padat penduduk yang berada di pinggir Sungai Angke (Aliran Pintu Air Cengkareng). 

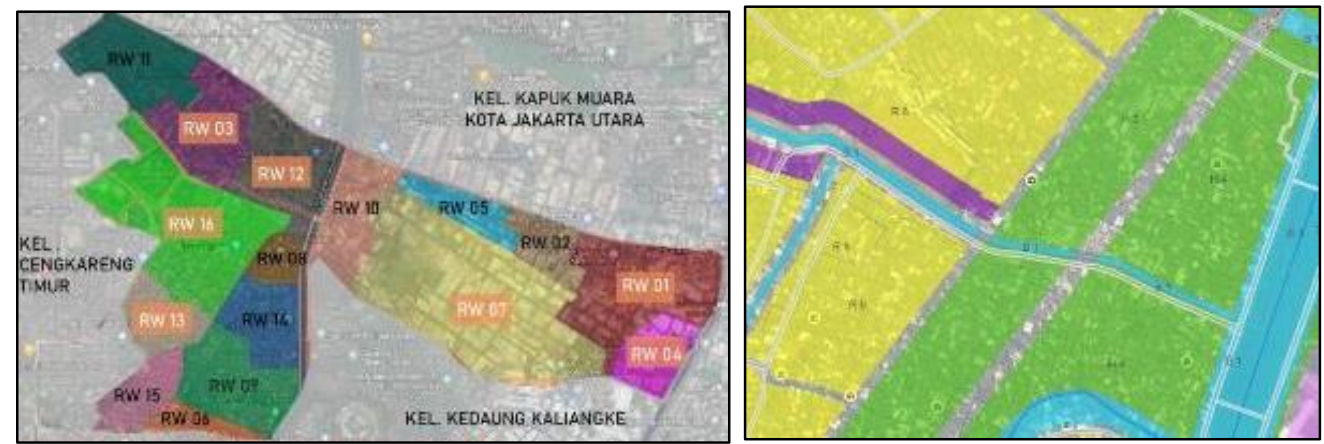

Gambar 4. RW di Kelurahan Kapuk (kiri), Permukiman kumuh di RW 12 (kanan)

Sumber : maps.google.com dan Jakarta Satu

\section{Analisis Tapak}

Tapak terletak di Jalan Royale Boulevard, RW 16, Kapuk, Cengkareng, Jakarta Barat. dengan lahan seluas $10.270 \mathrm{~m}^{2}$. Tapak memiliki zonasi lahan tipe R6 yang merupakan Sub Zona Rumah Flat. Tapak memiliki KDB 60\% (6.162 $\left.\mathrm{m}^{2}\right)$, KLB 2,4 (24.648 m²), KB 4, KDH $20 \%\left(2.420 \mathrm{~m}^{2}\right)$.
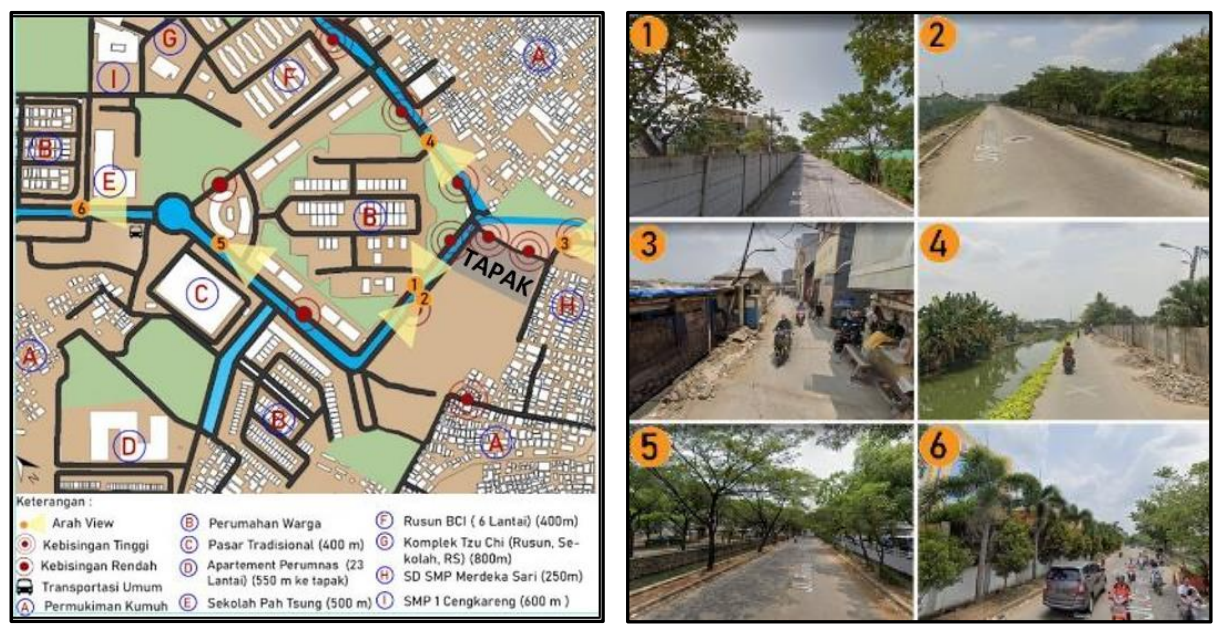

Gambar 5. Lokasi tapak dan keadaan sekitarnya Sumber data: maps.google.com

Tapak terletak di dekat permukiman kumuh dan liar yang ada di sisi timur dan utara tapak. Permukiman kumuh tersebut berada di pinggiran sungai. Untuk permukiman kumuh di utara tapak (RW12), jika dilihat dari peta zonasi Kecamatan Cengkareng seharusnya merupakan area RTH Kota.
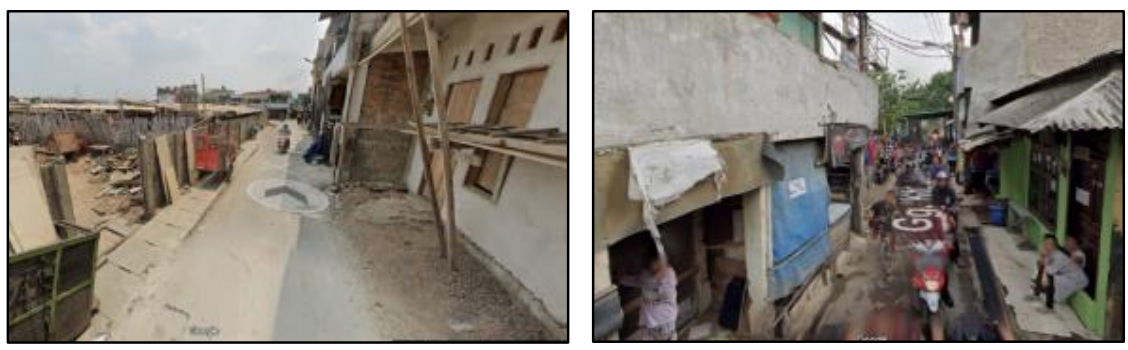

Gambar 6. Permukiman kumuh di sekitar tapak Sumber data: maps.google.com 
Untuk akses utama kendaraan dan pedestrian, berasal dari Jalan Royale Boulevard yang berada di depan tapak (garis merah pada gambar 7) yang memiliki lebar 8 meter. Jalan Royale Boulevard menghubungkan tapak dengan bangunan sekitar seperti pertokoan, perumahan, sekolah, pasar hingga halte Transjakarta 3E (Sentraland Cengkareng - Puri Kembangan). Untuk akses servis melalui Jalan Pedongkelan Baru yang berada di samping kanan tapak (garis biru pada gambar 7) yang memiliki lebar 5 meter.

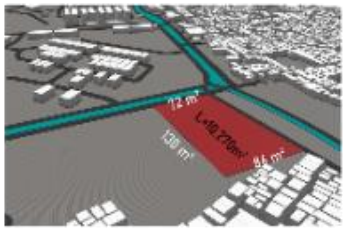

DIMENSIONS

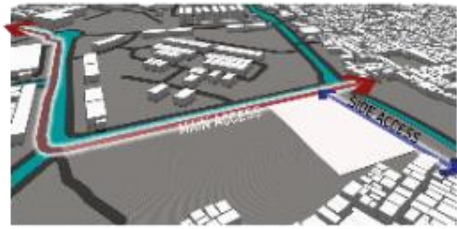

ACCESS

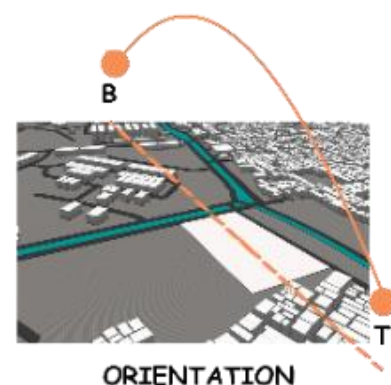

ORIENTATION

Gambar 7. Analisis tapak

Sumber : Penulis, 2021

Tapak berada di sumbu timur - barat, dengan sisi depan menghadap ke arah barat. sehingga untuk desain bangunan yang akan dirancang, sisi terpanjang bangunan akan menghadap ke arah utara - selatan untuk menghindari panas dan radiasi matahari dari arah timur - barat.

\section{Pembahasan}

Konsep yang digunakan dalam proyek rusunawa ini adalah konsep arsitektur berkelanjutan (ekologis), dan memenuhi kriteria hunian sehat. Konsep massa dan program bangunan memperhatikan kemudahan akses menuju ke tapak dan orientasi matahari.

Tapak menghadap ke arah barat, maka rencana penyusunan massa bangunan adalah memanjang dari sisi depan tapak (barat) ke belakang tapak (timur), agar sisi terpanjang bangunan menghadap ke sisi utara - selatan. Untuk pembagian fasilitas di lantai 1 , pada sisi yang berdekatan dengan jalan raya, maka dibuat menjadi fasilitas umum bagi masyarakat sekitar dan sisi yang cukup jauh dari jalan dibuat menjadi fasilitas bagi penghuni, serta pada tengah tapak dibuat menjadi area menanam bersama sehingga penghuni dapat menanam sayur dan buah untuk makanan sehari-hari.
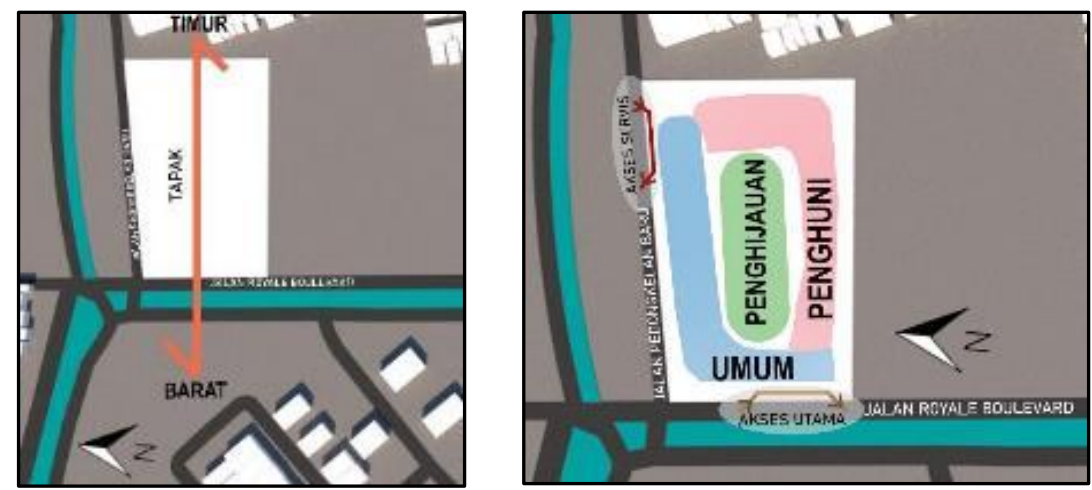

Gambar 8. Orientasi (kiri) dan zoning (kanan) terhadap tapak Sumber : Penulis, 2021 


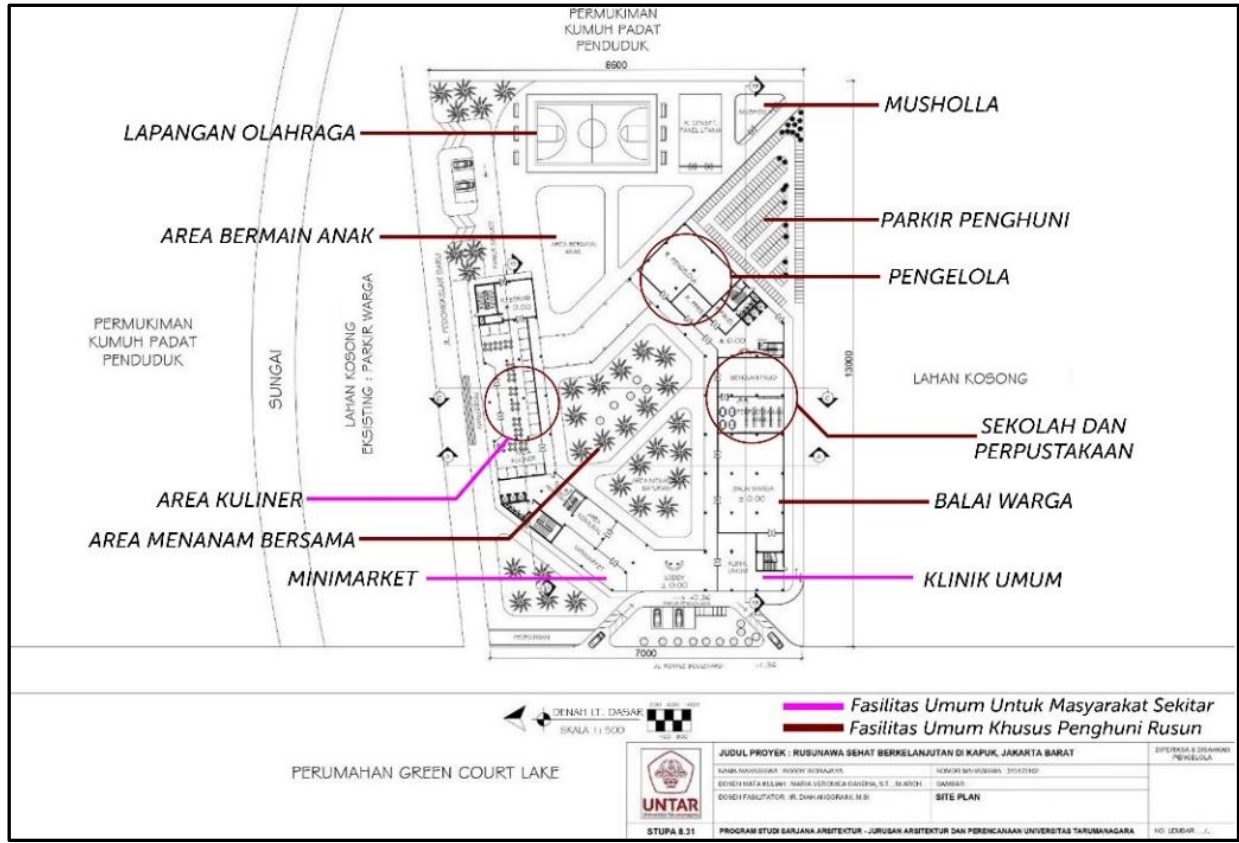

Gambar 9. Denah Lantai Dasar

Sumber : Penulis, 2021

Konsep berkelanjutan diterapkan pada bangunan dengan menghadirkan area menanam bersama di tengah tapak yang sekaligus berfungsi sebagai ruang terbuka hijau untuk area resapan air dan mengurangi polusi di kawasan sekitarnya. Untuk sistem kelistrikan bangunan, menggunakan 2 sumber utama dari solar panel dan PLN. Pada bangunan ini terpasang 1040 buah solar panel ( 640 buah di massa 1 dan 400 buah di massa 2) yang menghadap ke sisi utara tapak, dikarenakan letak garis khatulistiwa di Indonesia berada di sisi utara Pulau Jawa. Solar panel yang terpasang memiliki luas permukaan mencapai $578,448 \mathrm{~m}^{2}$, dan dapat menghasilkan $83.955,895 \mathrm{kwh} /$ bulan. Jika listrik yang dihasilkan dari solar panel tersebut, dibagi sama rata untuk setiap unit, maka setiap unit hunian akan mendapatkan 143,76 kwh / bulannya (dapat menghemat Rp211.000 per bulannya).

Bangunan juga menerapkan sistem rain water harvesting yang menampung air hujan yang berasal dari atap. Air hujan akan dibersihkan di bak filter sebelum dialirkan ke bak penampungan di basement untuk dapat dimanfaatkan penghuni rusunawa. Dengan penggunaan solar panel yang dapat menghasilkan listrik yang ramah lingkungan dan penerapan sistem rain water harvesting untuk menghemat penggunaan air bersih, dapat membantu meringankan beban ekonomi dari penghuni rusun yang merupakan Masyarakat Berpenghasilan Rendah (MBR).

Dengan penerapan konsep berkelanjutan pada tapak, sesuai dengan skala penerapan hunian berkelanjutan yang diungkapkan oleh Heinz Firck dan Rosilawati, proyek rusunawa ini telah berpartisipasi untuk mendukung kota yang berkelanjutan dan ramah lingkungan dengan menghemat penggunaan energi, menciptakan ruang hijau baik dari lahan eks permukiman kumuh dan penghijauan pada tapak perancangan, serta menghemat penggunaan air bersih dengan pengunaan kembali air hujan. 

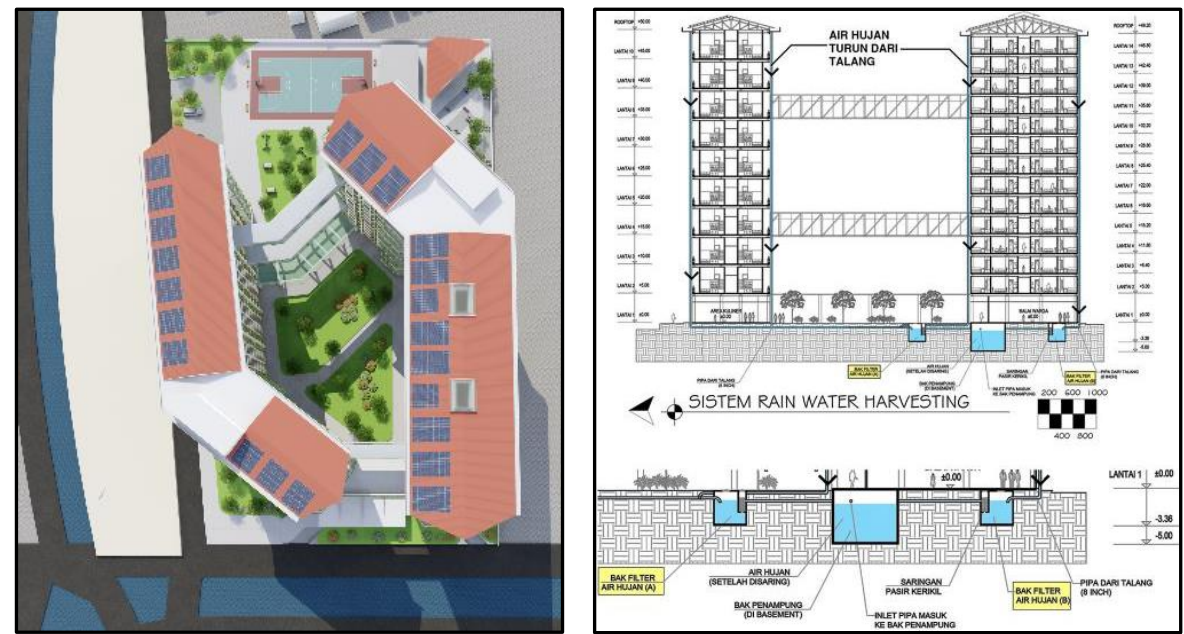

Gambar 10. Solar Panel (kiri) dan Rain Water Harvesting (kanan) pada bangunan Sumber : Penulis, 2021

Untuk konsep hunian sehat, diterapkan pada bangunan dengan merancang setiap unit agar nyaman dan sesuai dengan kebutuhan ruang penghuni yakni $9 \mathrm{~m}^{2} /$ orang. Untuk tipe $36 \mathrm{~m}^{2}$ dapat dihuni maksimal 4 orang, berbeda dari tipe $24 \mathrm{~m}^{2}$ yang dapat dihuni maksimal 3 orang.
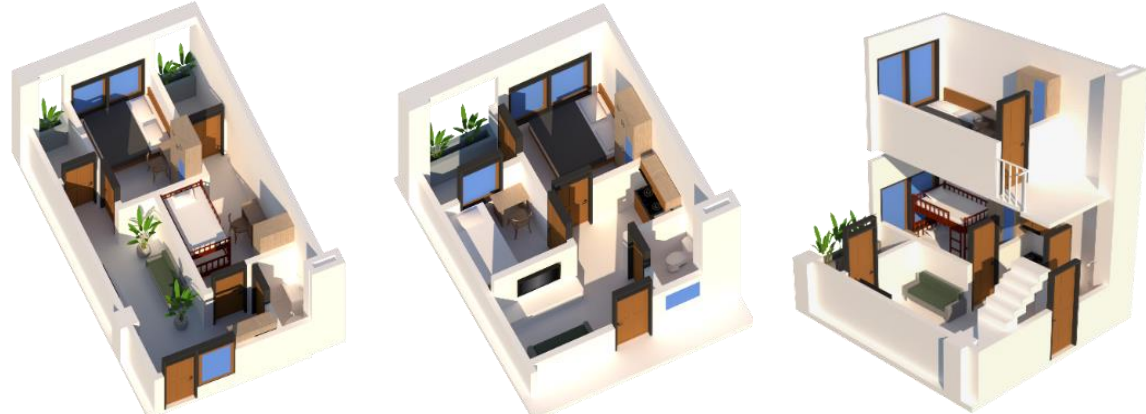

Gambar 11. Tipe $36 \mathrm{~m}^{2}$ (kiri), $24 \mathrm{~m}^{2}$ (tengah), 24+12 $\mathrm{m}^{2}$ tipe loft (kanan) Sumber : Penulis, 2021

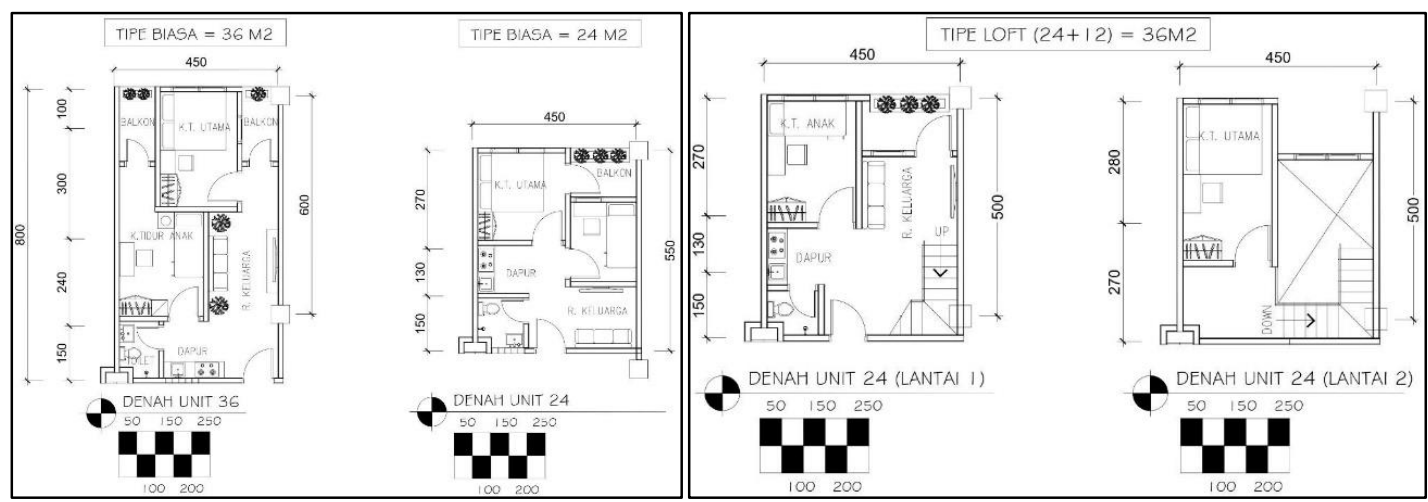

Gambar 12. Tipe $36 \mathrm{~m}^{2}$ dan $24 \mathrm{~m}^{2}$ (kiri), tipe $24+12 \mathrm{~m}^{2}$ loft (kanan)

Sumber : Penulis, 2021

Penerapan konsep hunian sehat juga dengan cara membuat bangunan memiliki pencahayaan alami dan sirkulasi udara alami yang baik sesuai dengan kriteria hunian yang sehat bagi penghuni sesuai dengan parameter Kemenkes RI, Kemen PUPR RI, dan American Public Health Association untuk mencegah berkembangnya bakteri dan virus dalam suatu ruangan. Cahaya matahari dan 
sirkulasi udara masuk dari skylight pada massa 1 dan dari ruang komunal yang ada di 2 ujung massa dan pada tengah massa. Massa dan setiap unit hunian ditempatkan menghadap ke arah utara selatan sehingga dapat memiliki pencahayaan alami secara maksimal sepanjang hari.
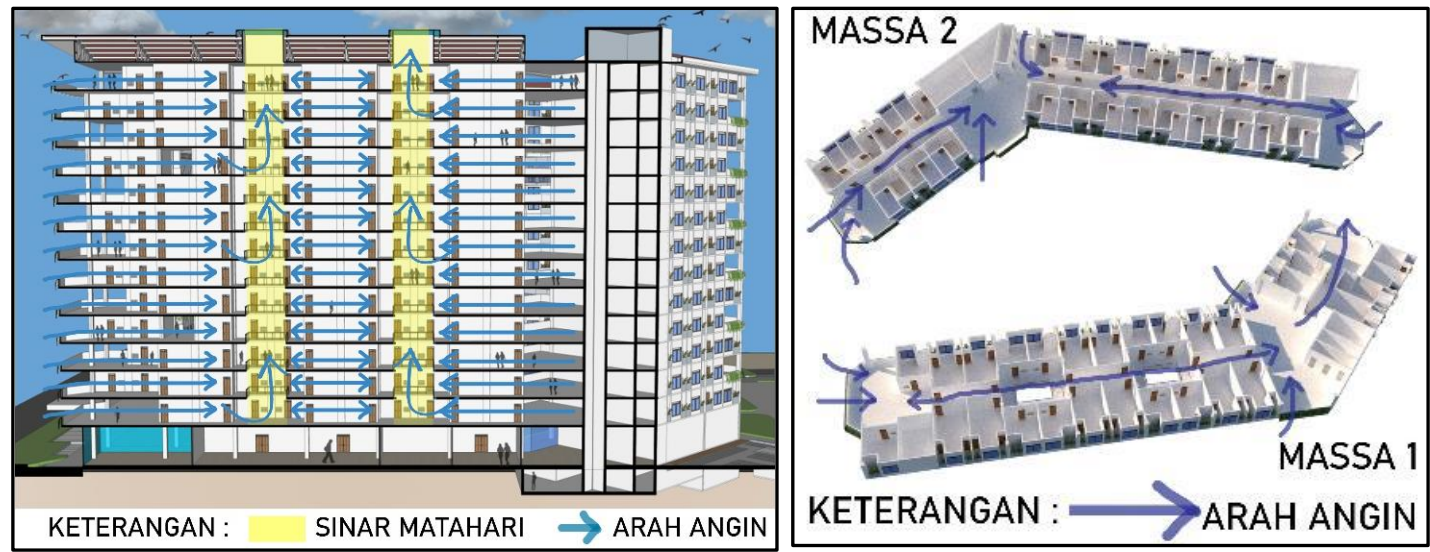

Gambar 13. Pencahayaan alami dan sirkulasi udara alami pada bangunan

Sumber : Penulis, 2021
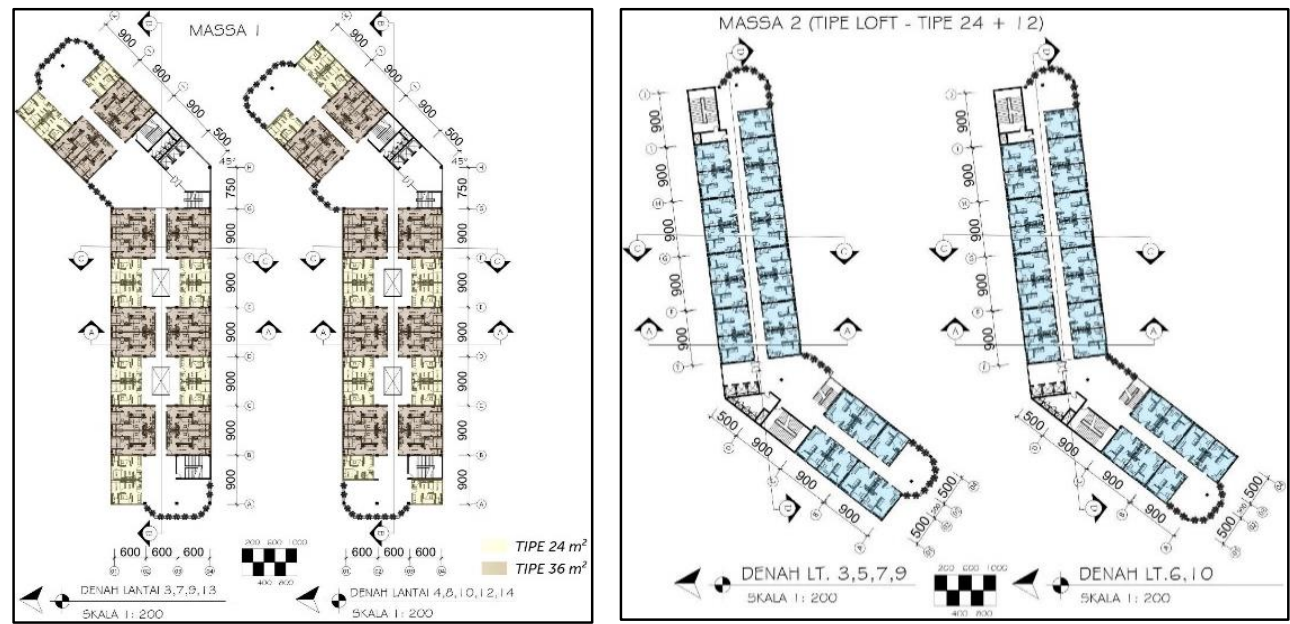

Gambar 14. Denah tipikal: massa 1 tipe 36 dan 24 (kiri) dan massa 2 tipe 24 loft (kanan) Sumber : Penulis, 2021
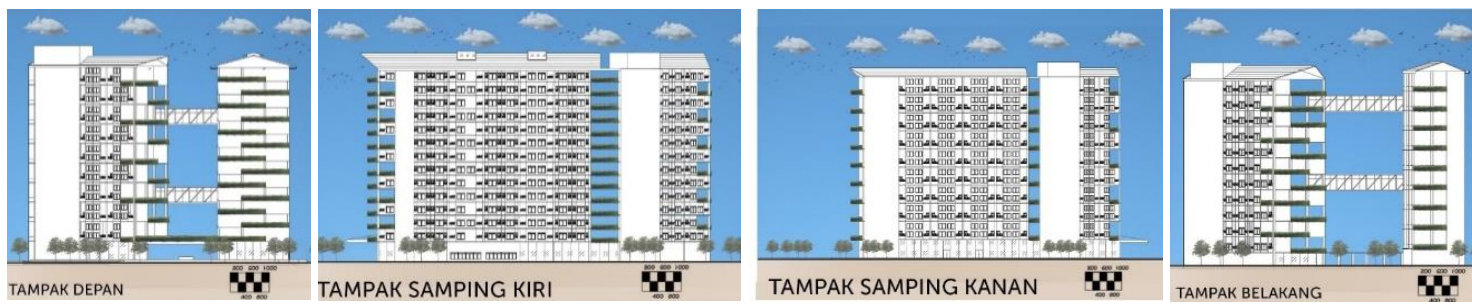

Gambar 15. Tampak Bangunan

Sumber : Penulis, 2021

Rusunawa ini memiliki ruang komunal di ujung koridor bangunan di setiap lantainya, yang berfungsi sebagai area kumpul penghuni dan sebagai tempat masuknya udara dan cahaya matahari ke dalam bangunan. Desain ruang komunal yang maju mundur dan bergantian pada kiri kanan meningkatkan estetika fasad bangunan, dan menghasilkan bayangan pada ruang di bawah untuk mengurangi panas matahari pada siang hari. 

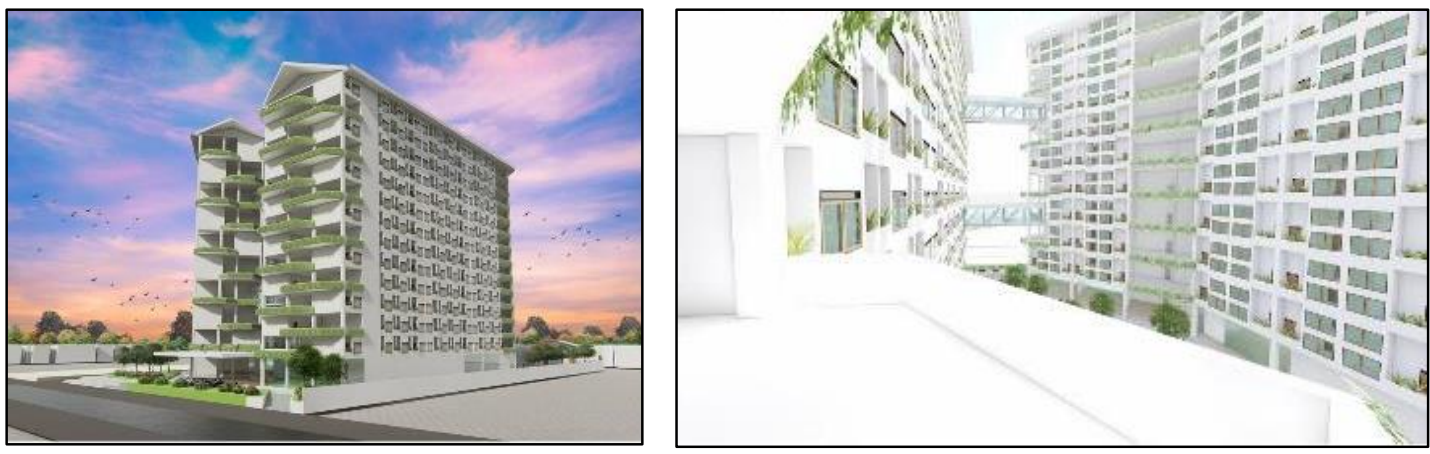

Gambar 16. Perspektif Eksterior (kiri), Ruang komunal per lantai (kanan)

Sumber : Penulis, 2021
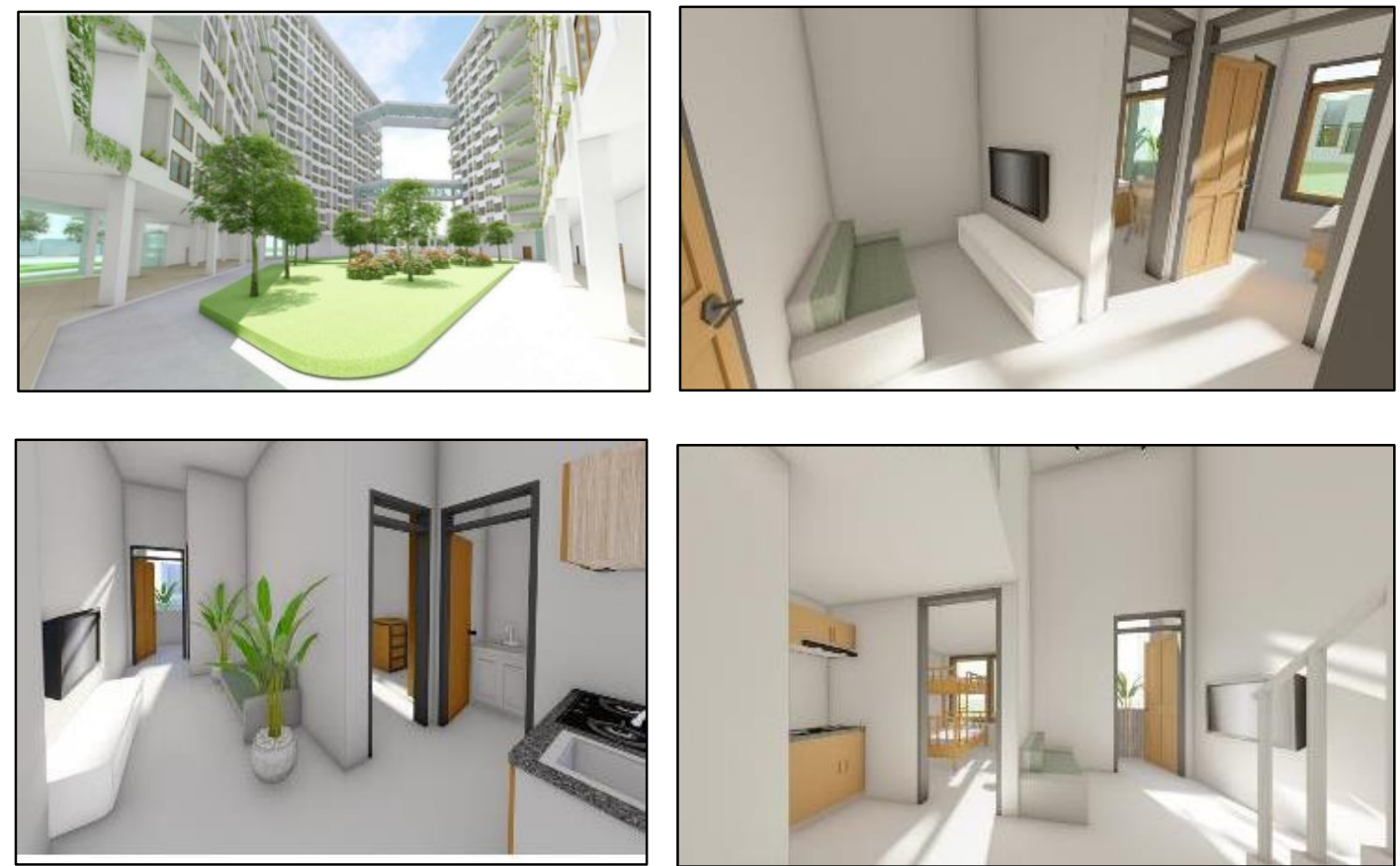

Gambar 17. Area menanam bersama (kiri atas), Hunian tipe 24 (kanan atas), Hunian tipe 36

(kiri bawah), hunian tipe 24 loft (kanan bawah)

Sumber : Penulis, 2021

\section{KESIMPULAN DAN SARAN}

Kesimpulan

Proyek "Rusunawa Sehat Berkelanjutan Bagi MBR di Kapuk, Jakarta Barat" dirancang sebagai salah 1 alternatif hunian dalam menjawab tantangan kepadatan penduduk di Jakarta, karena tingginya pertumbuhan penduduk yang ada sehingga akan membentuk suatu permukiman kumuh di berbagai sudut kota akibat dari terbatasnya lahan dan semakin mahalnya harga lahan di Jakarta.

Proyek rusunawa ini dirancang dengan konsep sehat dan berkelanjutan, yang mementingkan kesehatan dan kenyamanan dari penghuni rusunawa dengan menerapkan berbagai standar kesehatan dalam perancangan hunian. Bangunan ini juga menggunakan sistem penampungan air hujan untuk dapat dimanfaatkan kembali dan menggunakan salah satu sumber listrik yang berasal dari solar panel untuk menghasilkan listrik yang ramah lingkungan dan dapat membantu 
meringankan beban ekonomi dari penghuni rusun yang merupakan Masyarakat Berpenghasilan Rendah (MBR).

Dengan penggunaan sistem ramah lingkungan pada bangunan, diharapkan bangunan dapat membantu mewujudkan kota Jakarta sebagai kota yang berkelanjutan dan sesuai dengan target pembangunan SDG's dari PBB.

\section{Saran}

Dalam merancang sebuah hunian rusunawa bagi MBR, berbagai standar kesehatan, kenyamanan menjadi hal yang sangat penting agar hunian dapat menjamin kesehatan penghuni rusunawa. Sistem ramah lingkungan (berkelanjutan) juga sangat penting untuk diperhatikan dan diterapkan di berbagai kota-kota padat penduduk agar lingkungan di kota tersebut tetap sehat dan terjaga keberadaannya.

\section{REFERENSI}

Badan Pusat Statistik Indonesia. (2020). Provinsi DKI Jakarta Dalam Angka 2020. DKI Jakarta: Badan Pusat Statistik Indonesia .

Badan Pusat Statistik Jakarta Barat. (2020, September). Kecamatan Cengkareng Dalam Angka 2020 BPS Jakarta. Dipetik 21 Februari 2021, dari https://jakbarkota.bps.go.id/publication/2020/09/28/e91b1cfc1bf5b555046b9baf/kecam atan-cengkareng-dalam-angka-2020

Buchori, D. (2012, September). Diambil kembali dari Damayanti Buchori: http://damayanti.staff.ipb.ac.id/files/2012/09/Pendahuluan.pdf

Dirjen Cipta Karya . (1992). Pedoman Rumah dan Lingkungan Sehat. Jakarta.

Gischa, S. (2020, Juli 11). Kompas.com. Dipetik 12 Februari 2021, dari https://www.kompas.com/skola/read/2020/07/11/140300869/jumlah-penduduk-dunia2020

Hartinasari. (2018, September). SIMANTU (SISTEM MANAJEMEN PENGETAHUAN) PUPR. Dipetik 28 Februari 2021, dari https://simantu.pu.go.id/epel/edok/88c63_Riview_Rusun_Non_Modular_menjadi_Modul ar.pdf

Herlambang, S. (2021). Beyond Urban Ecology.

Himawan, A. (2016, Agustus 23). Suara.com. Dipetik 01 Maret 2021, dari https://www.suara.com/bisnis/2016/08/23/081313/menteri-basuki-tegaskan-rumahmbr-bukan-cuma-bagi-keluarga-miskin

Kementerian Kesehatan Republik Indonesia. (2013). Profil Kesehatan Indonesia 2012. Jakarta. Kementerian Pekerjaan Umum dan Perumahan Rakyat. (2010, Juli 19). Kota Tanpa Kumuh, Kementrian Pekerjaan Umum dan Perumahan Rakyat. Dipetik 19 Februari 2021, dari https://kotaku.pu.go.id/wartaarsipdetil.asp?mid=3049\&catid=2\&

Kementerian Permukiman dan Prasarana Wilayah. (2002). Kepmen Permukiman dan Prasarana Wilayah no 403/KPTS/M/2002 tentang "Pedoman Teknis Pembangunan Rumah Sederhana Sehat. Jakarta.

Menteri Pekerjaan Umum dan Perumahan Rakyat. (2020). Keputusan Menteri PUPR no 242/KPTS/M/2020. Jakarta: KEMENPUPR.

Menuju Pembangunan Permukiman yang Berkelanjutan, Tugas 2 Kajian Arsitektur Kota. (2020, April). Jakarta.

National Geographic Indonesia. (2019, Juni 19). National Geographic Indonesia. Dipetik 19 Februari 2021, dari https://nationalgeographic.grid.id/read/131760068/bikin-cemas-pbbbilang-indonesia-ikut-tanggung-jawab-dalam-ledakan-penduduk-pada-2050?page=all 
Putra, I. R. (2016, Oktober 03). Merdeka.com. Dipetik 12 Januari 2021, dari https://www.merdeka.com/uang/dunia-butuh-satu-miliar-rumah-baru-di-2025.html Rosilawati, H. (2016). TESIS RA142511 KONSEP HUNIAN BERKELANJUTAN PADA RUMAH SUSUN Studi Kasus Rusunawa Dupak Bangunrejo, Surabaya.

Sukawi. (2008). Ekologi Arsitektur : Menuju Perancangan Arsitektur Hemat energi dan berkelanjutan. Simposium Nasional RAPI VII 2008.

Sutanto, A. (2021). MELAMPAUI` EKOLOGI MENUJU ARSITEKTUR UNTUK KEBAIKAN dan KEHIDUPAN. Jakarta .

Undang-Undang No 11 tahun 2011 tentang Perumahan dan Kawasan Permukiman.

Undang-Undang No. 20 tahun 2011 tentang Rumah Susun.

WorldoMeter. (2020). Dipetik 18 Februari 2021, dari WorldoMeter:

https://www.worldometers.info/world-population/ 